\title{
Further Studies on the Pyrolysis of Polytetrafluoroethylene in the Presence of Various Gases
}

\author{
J. D. Michaelsen and L. A. Wall
}

\begin{abstract}
The thermal decomposition of polytetrafluoroethylene in the presence of gases or vapors has been explored in the range $450^{\circ}$ to $500^{\circ} \mathrm{C}$. Gases that have been used can be divided into three groups, depending on whether they inhibit, catalyze, or exert no effect on the thermal-decomposition process. Fluorine-containing gases, i. e., $\mathrm{ClF}_{3}$ and $\mathrm{IF}_{5}$, which are capable of dissociating at the pyrolysis temperatures to give fluorine atoms, showed the most marked inhibition yet observed. From the brevity of the duration of inhibition, it is concluded that the fluorine atoms directly attack the polymer to produce scissions through a metathetica! reaction.
\end{abstract}

\section{Introduction}

Polytetrafluoroethylene is the most thermally stable linear polymer known at the present time. Therefore, a considerable number of investigations have been carried out at the Bureau in an effort to extend its useful temperature range. Polymers of tetrafluoroethylene prepared with different catalysts $[1]^{1}$ or with admixed organic and inorganic solids [2] were found not to be different from commercial samples in their rates of thermal volatilization. The lack of inhibitory effects with the admixed solids and their obvious incompatibility with polytetra- fluoroethylene suggested that gases that could diffuse into the material would produce more pronounced effects. In a previous article [3] the results of such a study were reported. Both catalysis and inhibition were observed, although some gases or vapors produced no effect.

These results are interpreted in terms of freeradical chain mechanisms $[4,5]$, which are applicable to the degradation of numerous polymers. In the case of polytetrafluoroethylene the following mechanism appears applicable for its thermal decomposition in a vacuum or under nitrogen.

$$
\begin{aligned}
& \mathrm{P} \stackrel{k_{1}}{\longrightarrow} \mathrm{R}-\mathrm{CF}_{2}-\mathrm{CF}_{2}-\mathrm{CF}_{2} \cdot+\mathrm{R}-\mathrm{CF}_{2} \text {. } \\
& \text { Initiation } \\
& \mathrm{R}-\mathrm{CF}_{2}-\mathrm{CF}_{2}-\mathrm{CF}_{2} \cdot \stackrel{k_{2}}{\longrightarrow} R-\mathrm{CF}_{2} \cdot+\mathrm{CF}_{2}=\mathrm{CF}_{2} \\
& 2 \mathrm{R}-\mathrm{CF}_{2} \cdot \stackrel{k_{4}}{\longrightarrow} \mathrm{P} \text { or } 2 P \\
& \text { and/or } \\
& \mathrm{R}_{m} \mathrm{CF}_{2} \bullet \stackrel{k_{4}^{\prime}}{\longrightarrow} \text { evaporation } \\
& \}
\end{aligned}
$$

The $\mathrm{P}$ represents any size polymer, $\mathrm{R}$ is part of a polymer chain, the $k$ 's are the specific rate constants, and $\mathrm{R}_{m}$ is a chain of about 70 carbon atoms.

This picture of the degradation admits the possibility of inhibiting the weight loss of the polymer by increasing the probability of a termination step compared to the propagation (or depolymerization) step.

The earlier study [3] has shown that it is possible to inhibit the degradation of the polymer to some extent by a termination reaction in which a molecule or an atom from the gas combines with the polymer radical. However, along with this inhibition is a catalytic effect, presumably caused by the reaction of an atom with the polymer chain to give a new polymer radical. This catalytic effect also causes a drop in molecular weight. Specifically then, the applicable additional steps for the mechanism of this inhibition with hydrogen is

$$
\left.\begin{array}{c}
\mathrm{R}-\mathrm{CF}_{2}-\mathrm{CF}_{2} \cdot+\mathrm{H}_{2} \stackrel{k_{4}^{\prime \prime}}{\longrightarrow} \mathrm{R}-\mathrm{CF}_{2}-\mathrm{CF}_{2} \mathrm{H}+\mathrm{H} \cdot \\
\mathrm{R}-\mathrm{CF}_{2}-\mathrm{CF}_{2}-\mathrm{R}+\mathrm{H} \cdot \stackrel{k_{3}}{\longrightarrow} \mathrm{HF}+\mathrm{R}-\mathrm{CF}=\mathrm{CF}_{2}+\mathrm{R} \cdot \\
\mathrm{H} \cdot+\mathrm{H} \cdot \stackrel{k_{4}^{\prime \prime \prime}}{\longrightarrow} \mathrm{H}_{2}
\end{array}\right\}
$$


The effect of the $k_{3}$ step is to counteract the inhibition produced by the $k_{4}^{\prime \prime}$ step. The net result is a conversion of the unraveling mechanism to a random one, which initially has a very slow rate of volatilization but in subsequent stages becomes faster than the rate under vacuum. As the temperature is raised, the length of the inhibition period becomes less and less, until at $480^{\circ} \mathrm{C}$ or higher the over-all effect is catalytic.

From this mechanism it is to be expected that the best inhibition step is one in which a very strong bond is formed in the inhibition reaction, whereas a weak bond is formed in the catalytic reaction. In other words, if the inhibiting gas is AB, a strong $\mathrm{C}-\mathrm{A}$ bond is desired giving a very stable $\mathrm{B}$ radical so that $\mathrm{BF}$ is labile.

From a consideration of the bond-dissociation energies listed in table 1 it was conceivable that fluorine would have an inhibitory effect. The results of a study along these lines are reported here, along with some experiments with other gases and vapors and with more complicated mixtures, such as an $\mathrm{H}_{2}$ and $\mathrm{NO}$ mixture and $\mathrm{Cl}_{2}$ and $\mathrm{NO}$ mixture.

TABLE 1. Bond-dissociation energies [6]

\begin{tabular}{|c|c|c|c|}
\hline $\mathrm{X}$ & $X-X$ & $\mathrm{X}-\mathrm{F}$ & $\mathrm{C}-\mathrm{X}$ \\
\hline $\begin{array}{l}\mathrm{I} \\
\mathrm{Br} \\
\mathrm{Cl} \\
\mathrm{F}\end{array}$ & $\begin{array}{l}\text { kcal } \\
35 \\
45 \\
57 \\
37[7]\end{array}$ & $\begin{array}{l}k c a l \\
50[8] \\
60 \\
37[7]\end{array}$ & $\begin{array}{l}\text { kcal } \\
53[9] \\
65 \\
78 \\
114[10]\end{array}$ \\
\hline H & 100 & 148 & 90 \\
\hline
\end{tabular}

\section{Experimental Reagents}

The polymer used was in the form of a water suspension obtained from E. I. du Pont de Nemours \& Co., Inc., and designated by them as TD-3. The suspension was frozen and then dried in a vacuum while frozen, and the powder so obtained was used in the experiments.

The Freons were all from E. I. du Pont de Nemours \& Co., Inc., and the bromine, chloroform, cumene, pyridine, aniline, nitrobenzene, and benzaldehyde were obtained from Fisher Scientific Co. in the purest grades available. The $\mathrm{NO}, \mathrm{Cl}_{2}, \mathrm{ClF}_{3}$, and $\mathrm{H}_{2}$ were the purest obtainable from Matheson Co., Inc. The $\mathrm{IF}_{5}$ was obtained from the General Chemical Co. as research grade.

The $\mathrm{CF}_{3} \mathrm{I}$ was prepared in the Bureau according to the procedure of Henne and Finnegan [11] by the decomposition of perfluoro silver acetate in the presence of $\mathrm{I}_{2}$ and purification by distillation (bp$\left.-22^{\circ} \mathrm{C}\right)$.

\section{Experimental Procedure}

The rate of degradation was measured by determining the weight loss of the polymer after periodic heating under the various flowing gases. The sample of polymer was usually about $1 \mathrm{~g}$ in size and was placed in a porcelain boat for heating for all but the corrosive gases $\mathrm{ClF}_{3}$ and $\mathrm{IF}_{5}$. For these two gases the samples were heated in a nickel boat, which was found not to corrode during the course of the experiment.

The porcelain boats were heated in a glass tube surrounded with a brass furnace. The temperature was determined by a thermocouple placed in the tube so as to center the space above the porcelain boat. The temperature was regulated with a handoperated powerstat to $\pm 1^{\circ} \mathrm{C}$.

Because of the very corrosive nature of fluorine and the fluorine-halogen compounds, especially at the temperatures of pyrolysis, it was found by experience that a tube of nickel was needed to contain the reaction. For this purpose a special nickel tube was obtained, and its ends were machined so as to fit a 29/42 standard-taper joint. The rest of the apparatus leading to the tube and away from the tube was made of glass. It was attached to the nickel tube by means of two water-cooled joints. Although the glass would corrode during the experiments, this corrosion was slow compared with the over-all duration of the experiments.

A brass furnace placed around the nickel tube was used to bring the tube to the desired temperature. The temperature was measured in the space between the furnace and the nickel tube by an iron-constantan thermocouple. The ends of this space were plugged with asbestos paper.

A typical measurement was made by first placing the boat containing a weighed sample of the polymer in the unheated portion of the tube. The system was then thoroughly flushed with the gas or vapor under study, and a steady flow was established. The temperature of the furnace was brought up to, and maintained at, the desired level. The boat was pushed into the furnace. The manually operated variable transformer sometimes had to be readjusted in order to maintain the desired temperature. Temperature equilibrium was usually reached about 3 to 4 min after the introduction of the boat into the furnace. The time at which the temperature first reached the desired level was taken as the zero time for that particular run. At the end of a given interval of time, usually $1 \mathrm{hr}$, the boat was withdrawn from the furnace into the unheated part of the tube. This time was taken as the end of the interval of pyrolysis. Experience showed that it made no difference to the results whether the boat was withdrawn from the tube and allowed to cool to room temperature in the air or left to cool in the tube.

When pyrolyzed in a vacuum or under nitrogen, polytetrafluoroethylene was found to retain its original form [3]. In many of the experiments reported here the polymer became very fluid at the temperature of pyrolysis. Although the molecular weight of the polymer could not be determined quantitatively, this change in viscosity from a solid to what is often a very fluid liquid was taken as an indication of a very pronounced drop in molecular weight during the course of pyrolysis under the gases. 
The materials with boiling points above room temperature were usually introduced by passing nitrogen as a carrier through the liquid at room temperature and passing the $\mathrm{N}_{2}$ saturated with the vapor into the system. Water, however, was boiled directly into the flow system in which case the vapor pressure was near atmospheric.

\section{Results}

The gases studied are divided into three groups according to their effect on the rate of volatilization at $460^{\circ}$ and $470^{\circ} \mathrm{C}$ : (1) Those gases that exhibit a catalytic effect on the rate from the beginning of the study, (2) those that produce little or no effect on the rate, and (3) those that produce an initial inhibitory effect. The gases used and their effects are shown in table 2. Because it has been shown [3] that the rate under $\mathrm{N}_{2}$ (e. g., $0.017 \%$ per minute at $457^{\circ} \mathrm{C}$ ) is quite close to those observed previously under vacuum (e. g., $0.017 \%$ per minute at $453^{\circ} \mathrm{C}$ ) [12], the results under $\mathrm{N}_{2}$ are used as blank runs for comparison purposes in these experiments.

TABLE 2. Effect of various gases on the thermal decomposition of polytetrafluoroethylene

\begin{tabular}{|c|c|c|}
\hline Inhibitory & Catalytic & No effect \\
\hline $\begin{array}{l}\mathrm{IF}_{5} \\
\mathrm{ClF}_{3} \\
\mathrm{H}_{2^{\mathrm{a}}} \\
\mathrm{Cl}_{2} \mathrm{a} \\
\mathrm{Cl}_{2} \text { and } \mathrm{NO}(10: 1)\end{array}$ & $\begin{array}{l}\mathrm{H}_{2} \mathrm{Sa}^{\mathrm{a}} \\
\mathrm{H}_{2} \mathrm{O} \\
\mathrm{O}_{2}^{\mathrm{a}} \\
\mathrm{SO}_{2}^{\mathrm{a}} \\
\mathrm{NO}^{\mathrm{a}}\end{array}$ & $\begin{array}{l}\mathrm{N}_{2} \mathrm{a}^{\mathrm{a}} \\
\mathrm{C}_{6} \mathrm{H}_{5} \mathrm{CF}_{3} \mathrm{a} \\
\mathrm{Br}_{2} \\
\mathrm{CCl}_{3} \mathrm{H} \\
\mathrm{C}_{6} \mathrm{H}_{5} \mathrm{NH}_{2}\end{array}$ \\
\hline $\begin{array}{l}\mathrm{CCl}_{4} \mathrm{a}^{\mathrm{a}} \\
\mathrm{CClF}_{2} \mathrm{H} \\
\mathrm{C}_{6} \mathrm{H}_{5} \mathrm{CH}_{3} \mathrm{a} \\
\mathrm{C}_{6} \mathrm{H}_{5} \mathrm{NO}_{2} \\
\mathrm{C}_{6} \mathrm{H}_{5} \mathrm{CHO}\end{array}$ & $\begin{array}{l}\mathrm{H}_{2} \text { and } \mathrm{NO}(3: 1) \\
\mathrm{NH}_{3} \\
\text { Pyridine }\end{array}$ & $\begin{array}{l}\mathrm{CCl}_{2} \mathrm{~F}_{2} \\
\mathrm{CF}_{3} \mathrm{I} \\
\mathrm{CF}_{3} \mathrm{H} \\
\mathrm{Cl}_{2} \text { and } \mathrm{NO}(1: 1)\end{array}$ \\
\hline
\end{tabular}

a Previous work, reference [3].

\subsection{Catalytic Effect}

The curves representing the degradation of polytetrafluoroethylene under several gases and vapors exhibiting catalytic effects are shown in figure 1, in which the percentage of weight loss of polytetrafluoroethylene is plotted versus time. In these cases the slopes of the curves are greater than that of the blank, i. e., degradation under $\mathrm{N}_{2}$. The gases shown exhibiting this effect are $\mathrm{H}_{2} \mathrm{O}, \mathrm{NH}_{3}$, and a mixture of 3 moles of $\mathrm{H}_{2}$ to 1 mole of NO. Pure NO was previously found to be catalytic but not to the extent of this $\mathrm{H}_{2}$ and $\mathrm{NO}$ system, whereas, on the other hand, pure $\mathrm{H}_{2}$ was found to be an inhibitor at these temperatures [3]. The combination of $\mathrm{H}_{2}$ and $\mathrm{NO}$ seems to have the same effect as an increase in temperature does, i. e., decreases the period of inhibition. Because hydrogen atoms are most surely formed as intermediates in these reactions, it is possible that the NO could increase the steady state concentration of the atoms by catalyzing the rate of initiation of the over-all rate. A steady-state concentration of hydrogen atoms greater than the equilibrium value might have been indicated by the observation that

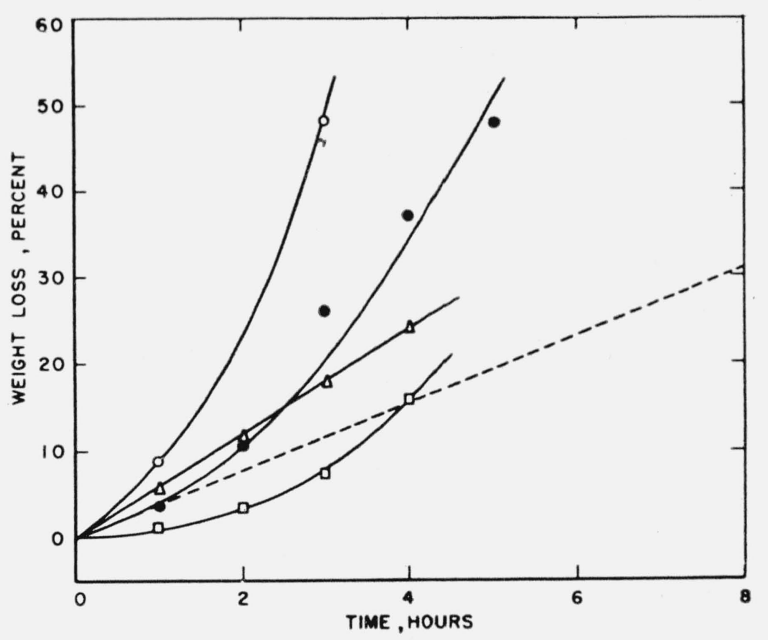

Figure 1. Pyrolysis of polytetrafluoroethylene in the presence of hydrogen-containing gases.

, Ammonia;, hydrogen and nitric oxide in $3: 1$ mole ratio; $\triangle$, water vapor; $\square$. hydrogen; dashed line, nitrogen; temperature $470^{\circ} \mathrm{C}$; pressure $\sim 1$ atmos phere.

the Nichrome wire would glow when inserted into the reaction system above the polymer. The catalysis of the recombination of the atoms on the metal giving a high heat of recombination could cause this. On the other hand, the hydrogen could have reacted with the $\mathrm{NO}$ on the wire to give a very exothermic reaction producing $\mathrm{N}_{2}$ and $\mathrm{H}_{2} \mathrm{O}$. Thus the water produced from the reaction of atomic hydrogen and NO, together with the NO might give the increased catalytic effect of the mixture. Water in a separate experiment was found to have a catalytic effect.

The catalytic effect of the water vapor seems to confirm the suspected polar or ionic character of the $\mathrm{C}-\mathrm{F}$ bond. This enhanced decomposition of the polymer in the presence of $\mathrm{H}_{2} \mathrm{O}$ parallels the behavior of metal fluorides.

The $\mathrm{NH}_{3}$, besides giving an over-all catalytic effect, was found to be incorporated in the polymer in large proportions. Because of this fact, little can be said about its mode of action.

\subsection{No Effect.}

Those compounds listed in table 2 that show no effect may have some influence on the rate at other temperatures and may interact with the polymer. However, at the temperatures at which these experiments were studied, i. e., $450^{\circ}$ to $480^{\circ} \mathrm{C}$, the rate of degradation of the polymer under these gases was, within a factor of two, the same as for $\mathrm{N}_{2}$.

It seems definite, however, that very little, if any, reaction is taking place between the degrading polymer and $\mathrm{CF}_{3} \mathrm{I}$ or $\mathrm{CF}_{3} \mathrm{H}$. This is extremely interesting and would seem to indicate either high $\mathrm{C}-\mathrm{H}$ and $\mathrm{C}-\mathrm{I}$ bond strengths in these compounds or an exceptional inertness of the $\mathrm{CF}_{3}$. radical. 


\subsection{Inhibitory Effect}

The best inhibitors, as a study of bond-strength data might lead one to expect, were those that decomposed to give $\mathrm{F}_{2}$, e. g., $\mathrm{ClF}_{3}$ and $\mathrm{IF}_{5}$. Their effects, when compared with those of $\mathrm{Cl}_{2}$ and $\mathrm{N}_{2}$, are shown in figure 2 ; the result that at $480^{\circ} \mathrm{C}$ these fluorine-containing halides exhibit only a catalytic effect is not shown. When in contact with the fluorine-containing gases the polymer liquefied, and the rate of weight loss approached or surpassed that caused by $\mathrm{N}_{2}$ after 5 to 7 hours at the indicated temperatures. Although a $1: 1$ mixture of $\mathrm{Cl}_{2}$ and NO gave but little effect, a 10:1 mixture had about the same effect as $\mathrm{Cl}_{2}$ alone, as shown in figure 3 .

The polymerization inhibitor, nitrobenzene, was found to be surprisingly good despite its low vapor pressure.

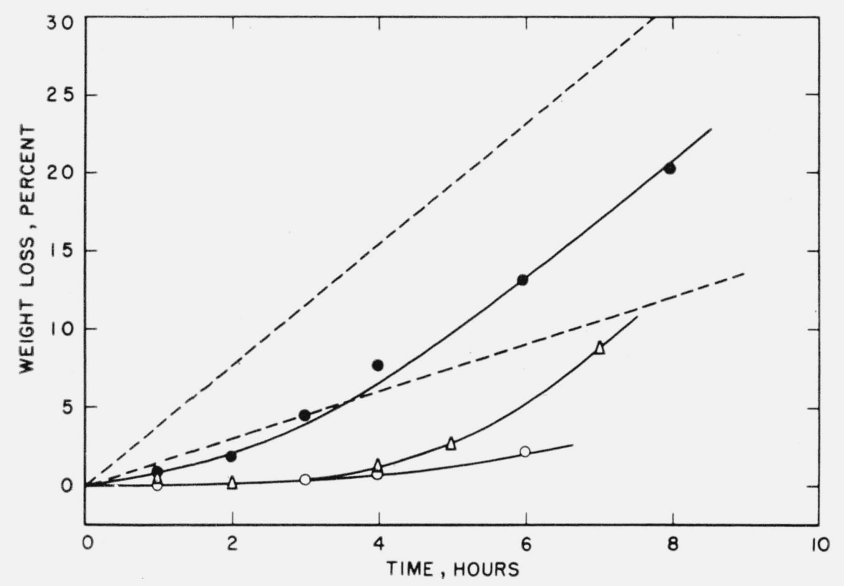

Figure 2. Pyrolysis of polytetrafluoroethylene in the presence of halogen gases.

, Chlorine at $470^{\circ} \mathrm{C} ; \triangle$, chlorine trifluoride at $470^{\circ} \mathrm{C}$; $\bigcirc$, iodine pentafluoride t $460^{\circ} \mathrm{C}$; upper dashed line, nitrogen at $470^{\circ} \mathrm{C}$; lower dashed line, nitrogen at $460^{\circ} \mathrm{C}$.'

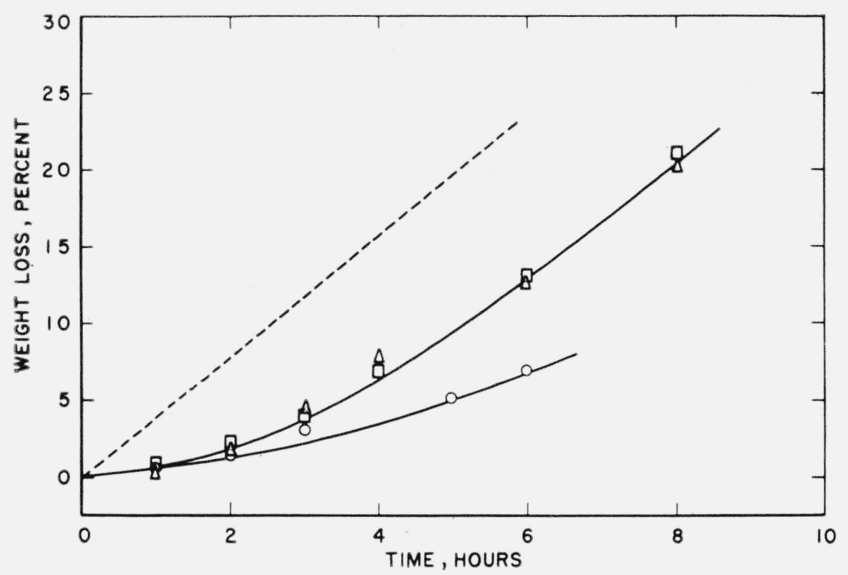

Figure 3. Pyrolysis of polytetrafluoroethylene in the presence of additional gases.

$\triangle$, Chlorine; $\square$, chlorine and nitric oxide in 10:1 mole ratio; $\bigcirc$, nitrobenzene; dashed line, nitrogen; temperature $470^{\circ} \mathrm{C}$.

\section{Discussion}

The aim of this work was to find an inhibitor for the thermal decomposition of the polymer that would be effective at $500^{\circ} \mathrm{C}$ and yet would not cause a rapid decrease in the molecular weight of the polymer. As pointed out in the introduction, the effort was directed to the search for a compound that would terminate the fluorocarbon radical, and still not produce in this reaction a radical that is too reactive. Fluorine was found to be the best inhibitor, but it still apparently caused a certain induced reaction or catalytic effect. There is very likely present a large concentration of $\mathrm{F}$ atoms because the bond energy of $\mathrm{F}_{2}$ is low. A lower concentration of $\mathrm{F}_{2}$, through the use of $\mathrm{IF}_{5}$ at its room-temperature vapor pressure, gave no significant increase in inhibition.

Thus, the rapid onset of fluidity in the polymer and the failure to obtain a longer inhibition time than that observed, suggest that $\mathrm{F}$ atoms attack the polymer chains in the following manner:

$$
\mathrm{F} \cdot+-\mathrm{CF}_{2} \mathrm{CF}_{2} \mathrm{CF}_{2} \longrightarrow \longrightarrow-\mathrm{CF}_{2} \mathrm{CF}_{3}+-\mathrm{CF}_{2} \text {. }
$$

Such reactions are probably more exothermic in the fluorocarbon system than in the corresponding hydrogen-hydrocarbon system. In the latter system the low probability of metathetical reactions has been studied theoretically [13] and experimentally [14]. An important objection to these reactions is the high energy of activation of these steps due to the shielding of the carbon and the low resonance energy in the activated complex resulting from the large displacement of the carbon atom from its equilibrium position.

In the fluorine-fluorocarbon system, however, no alternative low activation process is possible. Also, only a very few breaks need be induced by the above reaction for the process to be entirely random. If such a reaction is ruled out, then one needs to assume a very short kinetic chain length in order to explain the decomposition reaction in the absence of gases. However, this is contradicted by the observed kinetic behavior.

In the previous work [3] with $\mathrm{H}_{2}$ and $\mathrm{Cl}_{2}$ it was considered likely that the failure to obtain a greater degree of inhibition was the result of the attack reaction, $k_{3}$, by the $\mathrm{H}$ or $\mathrm{Cl}$ atoms formed by the inhibition reaction, $k_{4}^{\prime \prime}$ (see eq. 2). Consequently, the mixtures of gases, $\mathrm{H}_{2}$ with $\mathrm{NO}$, and $\mathrm{Cl}_{2}$ with $\mathrm{NO}$, were tried with the idea that one gas (NO) would inhibit the attack reaction, $k_{3}$. From table 2 it is clear that the results were in the opposite direction.

Along with these ideas and results may be placed the fact that an increase in temperature very rapidly increases the rate of catalysis relative to inhibition. Concurrently, changing the partial pressure of the inhibiting gas influences the ratio slightly. This indicates that the order of the rate of inhibition with respect to the inhibiting gas is different from that for the catalytic step. Therefore, steps $k_{3}$ and $k_{4}^{\prime \prime \prime}$ must both be important in the kinetic scheme proposed. 
This can best be seen from the following considerations. If a steady state in hydrogen atoms exists, then from equations $k_{4}^{\prime \prime}, k_{3}$, and $k_{4}^{\prime \prime \prime}$

$$
\begin{aligned}
d(\mathrm{H} \cdot) / d t=0=k_{4}^{\prime \prime}\left(\mathrm{RCF}_{2} \cdot\right)\left(\mathrm{H}_{2}\right)-k_{3}(\mathrm{H} \cdot)\left(\mathrm{R}-\mathrm{CF}_{2}-\mathrm{R}\right) \\
-k_{4}^{\prime \prime \prime}(\mathrm{H} \cdot)^{2} .
\end{aligned}
$$

When $k_{4}^{\prime \prime \prime}$ step is not important

Therefore,

$$
(\mathrm{H} \cdot)=\frac{k_{4}^{\prime \prime}\left(\mathrm{H}_{2}\right)\left(\mathrm{RCF}_{2} \cdot\right)}{\left(k_{3} R-\mathrm{CF}_{2}-R\right)} \cdot
$$

$$
\frac{\text { Rate of inhibition }}{\text { Rate of catalysis }}=\frac{k_{4}^{\prime \prime}\left(\mathrm{H}_{2}\right)\left(\mathrm{RCF}_{2}{ }^{\circ}\right)}{k_{3}(\mathrm{H} \cdot)\left(\mathrm{R}-\mathrm{CF}_{2}-\mathrm{R}\right)} .
$$

Substituting for (H.),

$$
\frac{\text { Rate of inhibition }}{\text { Rate of catalysis }}=\text { Constant }=1 \text {. }
$$

Therefore, varying the hydrogen-gas concentration should have no effect on this ratio nor should the temperature.

However, if $k_{4}^{\prime \prime \prime}$ step is very important, then to a first approximation

$$
(\mathrm{H} \cdot)=\left[\frac{k_{4}^{\prime \prime}\left(\mathrm{H}_{2}\right)\left(\mathrm{RCF}_{2} \mathrm{R}\right)}{k_{4}^{\prime \prime \prime}}\right]^{1 / 2} .
$$

Therefore, substituting for (H·),

$$
\begin{aligned}
\frac{\text { Rate of inhibition }}{\text { Rate of catalysis }} & =\frac{k_{4}^{\prime \prime}\left(\mathrm{H}_{2}\right)\left(\mathrm{R}-\mathrm{CF}_{2} \cdot\right)}{k_{3}\left[\frac{k_{4}^{\prime \prime}\left(\mathrm{H}_{2}\right)\left(R-\mathrm{CF}_{2}-\mathrm{R}\right)}{k_{4}^{\prime \prime \prime}}\right]^{1 / 2}} \\
& =\frac{\left[k_{4}^{\prime \prime} k_{4}^{\prime \prime \prime}\left(\mathrm{H}_{2}\right)\left(\mathrm{R}-\mathrm{CF}_{2} \cdot\right)\right]^{1 / 2}}{k_{3}\left(\mathrm{R}-\mathrm{CF}_{2}-\mathrm{R}\right)} .
\end{aligned}
$$

Consequently, by lowering the partial pressure of the inhibiting gas, there should be an increase in the catalytic effect relative to inhibition. Also, as an increase in temperature in these experiments decreases the inhibitory period, or rather markedly increases the rate of catalysis over a 10 to $20 \mathrm{deg} \mathrm{C}$ range, $E_{3}>>E_{4}^{\prime \prime}$, since $E_{4}^{\prime \prime \prime}=0$.

Therefore, once a free radical or atom is formed in step $k_{4}^{\prime \prime}$ that will enter into reaction in step $k_{3}$, it is better that $E_{3}<E_{4}$. Then inhibition increases faster with temperature than catalysis. No example of this type was observed in these experiments.

The results in table 2 show a few anomalies. The first is the inhibitory effect of $\mathrm{CCl}_{4}$ and $\mathrm{CClF}_{2} \mathrm{H}$ compared with no effect of $\mathrm{CCl}_{3} \mathrm{H}, \mathrm{CF}_{3} \mathrm{H}$, and $\mathrm{CCl}_{2} \mathrm{~F}_{2}$.

The effectiveness of the low-temperature polymerization inhibitors, nitrobenzene and benzaldehyde, is surprising. Their effect is to be contrasted with those of aniline, which gave no over-all effect at these high temperatures; pyridine, which acted much like ammonia; and benzotrifluoride, which had previously [3] been shown to have no effect. The aniline showed a slight inhibitory effect, but it was less than a factor of two at these temperatures. Its slight effect on the rate data could be attributed to its very slow solution into the bulk polymer.

According to the bond data given in table 1 and the discussion given in the introduction, the behavior of $\mathrm{Br}_{2}$ should contrast with that of $\mathrm{F}_{2}$. Bromine has no effect, whereas fluorine-containing halides are very good inhibitors, as can be seen in table 2 .

The results in general indicate that very good inhibitors for the thermal decomposition of fluorinecontaining polymers are within the realm of possibility. It is also evident from table 2 that relatively small changes in molecular structure or chemical composition play a large role in the behavior of a given substance. Thus achievement of the utmost possible degree of inhibition will require a large amount of investigation because of the obvious necessity to balance critically the various factors.

\section{References}

[1] R. E. Florin, L. A. Wall, D. W. Brown, L. A. Hymo, and J. D. Michaelsen, J. Research NBS 53, 121 (1954) RP2524.

[2] J. D. Michaelsen and S. Straus, NBS, unpublished experiments.

[3] L. A. Wall and J. D. Michaelsen, J. Research NBS 56, 27 (1956) RP2644.

[4] R. Simha, L. A. Wall, and P. J. Blatz, J. Polymer Sci. 5, $615(1950)$.

[5] R. Simha and L. A. Wall, J. Phys. Chem. 56, 707 (1952).

[6] A. G. Gaydon, Dissociation energies and spectra of diatomic molecules (Dover Publications, Inc., New York, N. Y., 1950).

[7] H. Wise, J. Phys. Chem. 58, 389 (1954).

[8] G. Herzberg, Molecular spectra and molecular structure: I. Diatomic molecules (Prentice-Hall, New York, N. Y., 1939).

[9] Measured by NBS Mass Spectrometry Section from $\mathrm{CH}_{3} \mathrm{I}$. (Private communication.)

[10] R. M. Potocki and D. E. Mann (informal communication).

[11] A. L. Henne and W. G. Finnegan, J. Am. Chem. Soc. 72, $3806(1950)$

[12] S. L. Madorsky, V. E. Hart, S. Straus, and V. A. Sedlak, J. Research NBS 51, 327 (1953) RP2461.

[13] F. O. Rice and E. Teller, J. Chem. Phys. 6, 489 (1938).

[14] R. E. Varnerin, J. Am. Chem. Soc. 7\%, 1426 (1955).

Washington, October 22, 1956. 